\title{
A cultura do silêncio: cultura de pobreza, dominação e pedagogia da libertação ${ }^{1}$
}

\section{The culture of silence: culture of poverty, domination and pedagogy of liberation \\ La cultura del silencio: cultura de la pobreza, dominación y pedagogía de la liberación}

\author{
ALBERTO SILVA \\ https://orcid.org/0000-0001-5345-9091 \\ Universidade de Estudos Estrangeiros de Quioto, KUFS \\ Instituto de Estudos Latino-Americanos \\ Quioto, Kansai, Japão \\ VALDEMAR SGUISSARDI \\ https://orcid.org/0000-0002-4150-2635 \\ Universidade Metodista de Piracicaba, Unimep \\ Programa de Pós-Graduação em Educação \\ Piracicaba, SP, Brasil
}

\section{É POSSÍVEL A IGUALDADE DE OPORTUNIDADES NUMA CULTURA DE POBREZA?²}

A publicação da última obra de Oscar Lewis ${ }^{3}$, Uma morte na família Sanchez. (ed. Gallimard, 1973), acaba de lembrar aos leitores franceses a obra do sociólogo americano que estes mesmos leitores haviam descoberto quando ele, dez anos atrás, publicara Os filhos de Sanchez: Até à morte ele fez a pobreza falar, dando-lhe uma escrita. Literatura da miséria, onde "se dá a palavra" aos pobres, enquanto Paulo Freire os leva a "tomar a palavra". O encontro deles aqui não é fortuito. Dois especialistas em educação, latino-americanos, questionam as pesquisas e as práticas desses dois autores para ver no que se transforma a educação, quando se defronta com as "culturas do silêncio". É claro que a escola, na medida em que

$1 \quad$ Artigo publicado originalmente em língua francesa em 1973, no periódico Orientations, França e traduzido em 2021 por um dos seus autores, Valdemar Sguissard, sendo respeitada a formatação original. Por isso não há resumo, abstract e resumen no artigo.

2 Apresentação em dois parágrafos dos editores de Orientations (N.T.).

3 Oscar Lewis (1914-1970), antropólogo norte-americano, foi best-seller mundial com diversas de suas obras, entre as quais destacam-se (títulos em português): “Os filhos de Sanchez" - autobiografia de uma família mexicana (transposto para o cinema, tendo o ator Antonny Quinn como protagonista no papel de Jesus Sanchez, o pai da família); "A cultura da pobreza - Cinco Famílias; A vida" - "Uma família porto-riquenha na cultura da pobreza"; "Uma morte na família Sanchez; Pedro Martinez" - "Um camponês mexicano e sua família”. (N.T). 
internaliza a dominação, ao mesmo tempo em que cria os meios de dominação de alguns sobre os outros, é impotente para enfrentar esse problema, pois não foi feita para isso.

Além disso, a cultura da pobreza questiona-nos sobre as características "opulentas" das reflexões e exigências de justiça e equidade social que se fazem nos países ricos: a justiça social, nestes defendida, com demasiada frequência esquece que condena irreparavelmente os países pobres ${ }^{4}$. É uma de nossas preocupações nesta revista, trazer à tona essa dimensão da ação política e educacional, especialmente no que se refere à extensão e ao desenvolvimento de nossos sistemas escolares. Vale lembrar, quando, por exemplo, notamos o lugar de Paulo Freire no Relatório da Comissão Internacional da UNESCO para o Desenvolvimento da Educação ${ }^{5}$.

\section{UMA OPÇÃO EM FAVOR DOS MARGINALIZADOS}

Nos últimos anos, a América Latina passou a ser conhecida na Europa como um continente diferente. Em primeiro lugar, pela sua situação particular no contexto internacional: o nosso continente nasceu fazendo parte de um mundo de pobreza e esta situação permanece essencialmente inalterada; há muito tempo, injustiças gritantes surpreendem cronistas e viajantes europeus. Mas a América Latina está também começando a se mostrar diferente na natureza e no estilo de sua reflexão e pesquisa. Isso é normal, pois seus problemas têm pouco a ver com os do Velho Mundo.

\section{A DESTITUIÇÃO DA LINGUAGEM}

Situações diferentes estimulam problemáticas originais e engendram novas modalidades de ação. É isso que queremos mostrar ao apresentarmos dois autores que levaram a sério o problema da pobreza na América Latina: o educador brasileiro, Paulo Freire, e o antropólogo norte-americano, Oscar Lewis, que, ainda que não sendo latino-americano, representa, entretanto, um tipo de reflexão latino-americana sobre o problema. Ambos centraram sua reflexão, e toda sua vida, em torno da preocupação - talvez a mais urgente e muitas vezes a mais esquecida neste continente dilacerado -: a miséria e suas consequências. Com perspectivas muito diferentes e objetivos que não se sobrepõem, aproximam-se

\footnotetext{
4 Cf. ILLICH, I. Energie et équité. Paris: Du Seuil, 1973, 58 p.

5 FAURE, E. et al. Apprendre à être. Fayard-Unesco, 1973. Cf. a análise que faz disso Paulo Latapi neste mesmo número.
} 
pela sua comum opção a favor da multidão de marginalizados que povoam nosso continente. Queriam mudar sua situação, cujo traço essencial concordam em denunciar: a pobreza significa, antes de tudo, a destituição da linguagem; pobre é aquele de quem se "roubou" a palavra. Decididos a devolver a linguagem aos dela despossuídos, diferem, porém, em seus métodos de ação. Para Oscar Lewis, trata-se, antes de tudo, de "dar a palavra" aos pobres, por meio dos estudos e publicações de estilo simples, com ar de verdade. Para Paulo Freire, os próprios pobres devem "tomar a palavra", e toda sua ação educativa baseia-se na convicção de que uma atitude ativa conduz, por si mesma, à superação da situação de pobreza.

Ao apresentar esses dois autores, estamos cientes de suas contribuições originais, que tentaremos, inicialmente, mostrar (primeira e segunda partes). Se os compararmos brevemente, é para melhor identificar seus respectivos pontos de vista sobre a organização da sociedade na América Latina (terceira parte). Isso nos permitirá levantar algumas questões sobre como conceber uma estratégia educacional que leve em conta a situação da América Latina. Antes que respondêlas, tentaremos fazer uma breve crítica à solução tradicional dada a esse problema, que consiste em procurar a igualdade de oportunidades através da escolarização massiva. Recordamos, por fim, que as objeções sugeridas também poderiam ser dirigidas aos sistemas educativos europeus, em particular o francês (quarta parte).

É óbvio que este artigo não é uma "comparação" ponto a ponto dos dois autores apresentados, mas sim uma justaposição decorrente do problema preciso de suas respectivas concepções da relação entre cultura e marginalidade (assim, por exemplo, não iremos expor a pedagogia de Paulo Freire e nem insistiremos nas pesquisas que Oscar Lewis planejava realizar em Cuba, quando poderia surgir o início de uma concepção pedagógica). Quanto ao conceito de "marginalidade", é importante também precisar que não pretendemos tomar partido no debate em torno deste conceito e suas implicações; tentaremos usar esta palavra para designar simplesmente a situação daqueles que vivem geográfica ou funcionalmente fora dos centros de produção, de decisão e de cultura.

\section{OSCAR LEWIS: A DESCOBERTA DE UMA "CULTURA DE POBREZA"}

O antropólogo Oscar Lewis acabou por falecer enquanto trabalhava intensamente na América Latina. Ao longo de sua vida, cada livro publicado a partir de suas pesquisas nas favelas ou slums, em geral, provocou vivas polêmicas sobre os temas tratados e os métodos empregados. Dada a sua morte prematura, é chegada a hora de um balanço: diversas publicações organizaram mesas- 
redondas, com pesquisadores, sobre o trabalho desse professor, de um país rico, profundamente preocupado com a vida cotidiana nos países pobres. Ao apresentar seus pontos de vista, não pretendemos, de forma nenhuma, refazer esse balanço, mas simplesmente destacar alguns pontos-chave de sua reflexão e as questões metodológicas que esta nos coloca.

É importante sublinhar, desde logo, que Oscar Lewis jamais se pôs como um expectador externo da vida que ele descreve. Dela participa e não visa a uma "objetividade" que consistiria em lançar um olhar frio ou em adotar uma atitude neutra que lhe parecesse de imediato impossível. Se ele estuda as pessoas dos guetos urbanos, de Porto Rico a Nova Iorque, ou dos bairros periféricos do México, é que quer fazer conhecer essas pessoas mediante o que elas falam de si. Seus livros apresentam-se, então, como um relato exaustivo das conversações que manteve com os membros da família escolhida, como fonte de informações. Sua abordagem apoia-se, desse modo, sobre uma opção humanista que ele não esconde. Pensa, de fato, que sua perspectiva é não somente científica, mas também social, pois pretende contribuir, de certa forma, para "promover" pessoas até então ignoradas. Ele mesmo o diz: "Eu cresci na conviç̧ão de que os antropólogos devem exercer uma nova função no mundo moderno: servir, enquanto pesquisadores, como porta-vozes da grande massa dos marginalizados do mundo subdesenvolvido que constitui quase $80 \%$ da população mundial.”

\section{APRESENTAÇÃO DO MÉTODO}

O método utilizado decorre inteiramente dessa opção inicial. Seguindo a tradição antropológica de Linton, ele centra o problema sobre as relações entre a cultura e a personalidade. É, de fato, a personalidade dos "informantes" escolhidos que mostra o melhor de sua própria cultura. Por isso, a importância de escolher bem os "casos representativos" e de obter das entrevistas o máximo de informação que permita reconstituir, mediante os casos escolhidos, a vida do conjunto da população. Por outro lado, quem estuda a etnografia não deve colocar-se à margem das pessoas estudadas. Lewis pensa - e nisto é fiel discípulo de Malinowski - que o antropólogo deve não somente viver na comunidade em estudo, mas falar a língua local e também compartilhar da totalidade da vida da população em questão. Isto lhe faz escolher a família como unidade de análise?

6 LEWIS, O. Five families: mexican case studies in the culture of poverty. New York, Basic Books, 1959, p. 15.

7 LEWIS, O. The Children of Sanchez. New York, Random House, 1961 (ed. espanhola: p. XXI). Tradução francesa: Les enfants de Sanchez. Éditorial Gallimard.

LEWIS, O. La Vida. A Puerto Rican Family in the Culture of Poverty. New York, 1966 (ed. francesa: p. 773).

964 - Rev. Bras. Polít. Adm. Educ. - v. 37, n. 2, p. 961 - 985, mai./ago. 2021 
Chegando ao vilarejo ou bairro para estudar, Lewis entra em contato com a população mediante uma ou várias conversas informais. Ele chega, pouco a pouco, à família que pode exercer o papel de informante com especial eficiência. Escolhe essa família, mas, de fato, a escolha é mútua, no sentido de que Lewis entende-se bem com os membros da família que aceitam, por simpatia ou por confiança em relação ao pesquisador, responder às perguntas que este fará. Durante as entrevistas individuais ou de grupo, Lewis inteira-se da vida dessa família. Cada um, por sua vez, fala de sua própria vida e de suas relações com seus pais. Lewis grava, naturalmente, essas conversações, reescuta-as, faz novas perguntas e obtém informações complementares. Após certo tempo, o retrato da família estava completo. O pesquisador pôde conhecer suas ações e sentimentos. Até os pensamentos mais secretos foram revelados. Graças à sua identificação com as pessoas estudadas e porque a descrição etnográfica foi feita pelos próprios envolvidos, Lewis pôde obter uma grande precisão e sutileza na reconstrução posterior do caráter dos indivíduos pesquisados, quando da publicação das entrevistas ${ }^{8}$.

Ele pôde, assim, estudar, entre 1951 e 1970, um número de famílias pertencentes a populações marginalizadas situadas nas regiões de língua espanhola, vizinhas dos Estados Unidos: o vilarejo de Tepostlan, no México; numerosos casos de famílias da província e da cidade do México; e o caso de uma família porto-riquenha, vivendo, com intermiência, entre as cidades de São João (de Porto Rico) e Nova Iorque. Lewis tinha também tentado uma análise comparativa entre as "culturas camponesas" do México e da Índia. Além disso, deixou numerosos artigos sobre seu método e sobre certos problemas teóricos postos ao longo de suas pesquisas?.

\section{A “CULTURA DE POBREZA"}

O que tem sido objeto invariável de suas pesquisas e, ao mesmo tempo, o tema essencial das reflexões teóricas nelas inspiradas, é o conceito de "cultura de pobreza". Foi ele, precisamente, que the popularizou o uso nos Estados Unidos e na América Latina. Porque, em seu modo de ver, "dar a palavra" aos marginalizados mexicanos e porto-riquenhos não significava glorificar a pobreza de forma romântica, mas dar testemunho de uma vontade de reunir uma série

\footnotetext{
8 Ver VALENTINE, C. Culture and Poverty. Critique and Counterproposals. University of Chicago Press, 1968. p. 48-77.

$9 \quad$ Ao longo destas notas apresentaremos as principais obras de O. Lewis.
} 
de elementos característicos permanentes que poderiam ser descobertos nas populações que vivem nas condições sociais, psicológicas e econômicas da marginalidade.

Para construir o conceito de "cultura de pobreza", Lewis distingue, inicialmente, cultura de subcultura. A pobreza está na origem de uma subcultura, no sentido de que ela constitui um subsistema conectado ao sistema social global pelo qual ela, em última análise, se explica. Numa primeira aproximação, portanto, uma subcultura de pobreza explica-se pelo sistema cultural de sua própria sociedade ${ }^{10}$. Mas a pobreza engendraria, igualmente, de forma relativamente autônoma, uma série de modelos de comportamento e de ação que sobrevivem persistentemente de geração em geração. Segundo Lewis, a pobreza seria, portanto, um estado de privação econômica, de desorganização social e de carência generalizada. Ela seria também algo de positivo, possuindo uma estrutura característica, uma posição racional e certos mecanismos de defesa, sem os quais os pobres dificilmente poderiam subsistir ${ }^{11}$. Os pobres teriam, portanto, uma cultura própria como consequência de seu sistema de vida notavelmente estável. Este se transmite de pai a filhos como uma coleção de saber-fazeres, de técnicas de sociabilidade e de crenças. Esta transmissão realiza-se pela vivência familiar. Lewis considera a família, antes mesmo de todas as outras redes sociais, como o núcleo primário de formação e sobrevivência culturais.

\section{QUEM SÃO OS POBRES?}

Questão essencial. Numa palavra: os pobres são basicamente os marginalizados. Já se acreditou que a marginalidade se situava em algum lugar, que se poderia localizá-la no espaço por critérios geográficos. A marginalidade encontrava-se, por exemplo, no campo ou nos bairros periféricos. Análises sociológicas e antropológicas permitiram, mais tarde, a descoberta de que a marginalidade era antes "funcional", porque ela não se define em relação a um centro físico ou visível da sociedade, mas em relação ao centro do próprio sistema social. Seriam, então, marginalizados todos aqueles que vivem fora dos circuitos de produção econômica, de criação cultural ou de decisão política desse sistema. Lewis pensa em termos de marginalidade funcional e considera como fazendo parte do mesmo mundo os moradores expulsos dos terrenos mais cobiçados,

10 C. Valentine oferece diversas precisões sobre a pobreza como subcultura na concepção de O. Lewis. Op. cit. p. 3 e 129. Acerca do sucesso do conceito de "cultura de pobreza", pode-se sinalizar que a tradução francesa do livro de R. Hoggart, The Uses of Literary, traz como título, 13 anos após, a edição inglesa: $A$ cultura do pobre.

11 LEWIS, O. La Vida. Op. cit., p. 800-810.

966 - Rev. Bras. Polít. Adm. Educ. - v. 37, n. 2, p. 961 - 985, mai./ago. 2021 
os habitantes dos bairros periféricos, mas também os desempregados crônicos, os habitantes dos cortiços do centro da cidade e mesmo os emigrados em Nova Iorque; em uma palavra, os miseráveis ou a classe baixa que vive nos guetos, social e culturalmente ${ }^{12}$. Empregando uma terminologia diferente, pode-se dizer que Lewis, quando fala de "cultura de pobreza", pensa antes de tudo no lumpemproletariado, esta massa heterogênea "que está nos níveis mais baixos da escala socioeconômica"13.

\section{SUAS ORIGENS}

É comum, segundo Lewis, que a "cultura de pobreza" ocorra quando um sistema social e economicamente estratificado sofre um processo de desintegração ou de substituição por outro. É o caso da transição do feudalismo para o capitalismo, ou durante a revolução industrial. Ela pode resultar igualmente de uma conquista imperial ou de um destribalização, como seria, segundo ele, o caso na África. No caso do México, tratar-se-ia antes de um fenômeno típico de muitas sociedades estáveis. De fato, nas sociedades estudadas por Lewis, a criação pelas camadas subproletárias de uma subcultura própria é uma consequência necessária da dupla marginalização sofrida por essas populações. Marginalidade, antes em relação a seu mundo rural (de onde provêm na sua imensa maioria): eles abandonam o campo, ainda que guardando um conjunto de valores, de maneiras de pensar e de agir, de comunicar, isto é, globalmente, uma cultura. Marginalidade, depois, em relação à cidade que os levou a deixar o campo sem os aceitar em seu seio. Ao desenraizamento se junta sua vida periférica. Sua fuga completa-se, finalmente, pela desintegração: eles abandonaram um mundo para entrar em outro, mas terminam, a um só tempo, por ser excluídos dos dois. Daí o desemprego, a instabilidade e as condições de vida miseráveis. Daí os esforços para sobreviver a essa situação enquanto permanecem nela.

A "cultura de pobreza" seria, assim, uma reação contra esse estado de coisas, ao mesmo tempo em que uma adaptação dos pobres a sua condição marginal em relação a uma sociedade de tipo capitalista, altamente individualista ${ }^{14}$. Além das diferenças regionais ou nacionais, a "cultura de pobreza" teria traços permanentes: diante da impossibilidade de ascender na escala social, diante do

\footnotetext{
12 Ver VALENTINE, C. Op. cit., p. 18-19.

13 LEWIS, O. The Children of Sanchez, edição espanhola, p. XV.

14 LEWIS, O. The Children of Sanchez, edição espanhola: p. XIII.
} 
sistema exclusivo e fechado, organizado para e pelos ricos, os marginalizados desenvolveriam um modo de vida particular que persistiria enquanto as condições sociais permaneçam as mesmas ${ }^{15}$.

\section{DESCRIÇÃO DA “CULTURA DE POBREZA”}

Lewis propõe uma meia centena de características próprias da "cultura de pobreza". Tentando identificar-lhe todas as dimensões econômicas e psicossociais, afirma poder construir um modelo conceitual provisório dessa cultura.

No México, a cultura de pobreza inclui ao menos um terço da população... Esta população se caracteriza por uma taxa de mortalidade relativamente mais alta, uma esperança de vida menor, uma maior proporção de indivíduos nas faixas etárias mais baixas e, em razão do trabalho infantil e feminino, por uma mão de obra mais numerosa ${ }^{16}$.

Ainda no México, trata-se de uma cultura provinciana e orientada localmente.

Estes membros integram-se de uma maneira muito parcial às instituições nacionais e são "marginalizados", ainda que habitem no centro de uma cidade grande. Na cidade do México, por exemplo, os pobres, em sua maior parte, possuem um nível de educação e de alfabetização muito baixo, não são filiados a sindicatos de trabalhadores e não são membros de nenhum partido político. Não são beneficiários da seguridade social e também não se utilizam dos serviços sanitários, administrativos, religiosos ou culturais da cidade. Do ponto de vista econômico, aos salários muito baixos se juntam, entre outros, o desemprego permanente ou parcial, uma extrema diversidade de empregos, a ausência de qualquer reserva monetária ou alimentar, a proliferação dos sistemas locais de empréstimos e de penhores. Enfim, uma sumária caracterização social e psicológica obriga a incluir a falta de vida privada, um forte senso gregário, o uso frequente da violência na educação das crianças, uma sexualidade muito precoce, uniões livres, uma nítida tendência de constituir famílias centradas na mãe, insegurança, sentimento de inferioridade, resignação, fatalismo ${ }^{17}$.

15 LEWIS, O. La Vida, edição francesa: p. 800 ss.

16 LEWIS, O. The Children of Sanchez (edição espanhola: pp. XV-XX). Em La Vida, Lewis adianta uma definição mais precisa, ainda que mais genérica: "A cultura de pobreza pode nascer em todos os tipos de contextos históricos. Ela, entretanto, tende a crescer e florescer em sociedades que apresentam as seguintes condições: 1) uma economia baseada no dinheiro líquido, os salários e a produção com fins de lucro; 2) uma taxa de desemprego constantemente elevada e de subemprego para a mão de obra não qualificada; 3) baixos salários; 4) a incapacidade de oferecer uma organização social, política e econômica para uma população de baixa renda, seja como voluntária, seja imposta pelo governo; 5) a existência de um sistema parentesco bilateral antes que unilateral; 6) a existência de uma escala de valores na classe dominante que valoriza a acumulação de riquezas e de bens, em lugar da possibilidade de progressão e de poupança, e que considera o baixo status econômico como sendo resultado de uma inferioridade pessoal." (edição francesa, pp. 801-802).

17 Ibidem. 
Além dessa multiplicidade de características, importa anotar o que assegura sua unidade. Trata-se de um sistema permanente de "respostas" aos problemas postos por sua vida e, neste sentido, é uma cultura. Entretanto, são respostas a problemas imediatos, locais, que as instituições existentes foram incapazes de resolver. Isso parece sugerir que esta "cultura de pobreza" é, em grande medida, uma subcultura dependente, subsidiária, uma consequência ou um reflexo da estrutura social global, à que falta, portanto, uma autonomia própria. Mas Lewis jamais a considerou assim: ele tendia a pensar que a pobreza poderia ser a fonte de uma cultura autônoma.

\section{OS PONTOS POSITIVOS}

As obras de Lewis fornecem uma abundante informação sobre a vida e a mentalidade das famílias entrevistadas. Essa população foi, em geral, escolhida entre as mais marginalizadas. Apesar das diferenças de costumes e linguagem, algo parece inicialmente certo: a marginalidade abunda na América Latina e encontrase por toda a parte em grande quantidade. Lewis descreve certas situações de modo sugestivo e caloroso de alguém que tem de fato participado da vida de que fala, ou melhor, que faz falar, porque ele se propõe a respeitar estritamente os longos depoimentos de Jesus, de Consuelo, de Pedro Martinez e de Fernanda, e de muitos outros. Deixa exprimirem-se os pobres para chocar os ricos, empregando a "cultura de pobreza" para torná-los conscientes desta "pobreza de cultura", que parece caracterizar, cada vez mais, largas frações conformistas da sociedade norte-americana. Seu método acomoda-se bem a seu propósito.

Em suas obras, Lewis desafia abertamente uma ciência social excessivamente apoiada sobre a medida da quantidade, mostrando o valor imperecível dos elementos sensíveis e dramáticos da realidade, empregando com intensidade técnicas "qualitativas" que ajudaram, eficazmente, a melhorar ${ }^{18}$. Consequência previsível de seu apego ao concreto: um olhar cheio de afeição para aqueles que não eram simples objetos de estudo, mas parceiros que lhe permitiam falar do problema que mais o havia preocupado durante sua vida profissional. Os pobres, naturalmente inclinados à desconfiança, confiaram nele, dandolhe informações que enriquecem a literatura sociológica sobre as condições psicológicas da emigração, sobre a vida sexual das populações marginalizadas e, em geral, sobre os mecanismos ideológicos do subproletariado mexicano e porto-riquenho. Os resultados de suas pesquisas não parecem imediatamente generalizáveis à totalidade dos países da América Latina. Entretanto, podem, 
talvez, permitir levantar certas questões sobre as relações entre a cultura e o sistema social. Se é de fato verdade que o sistema de valores dos subproletários mostra muitas "qualidades" que são menos frequentes em outras camadas sociais - senso de solidariedade, integração da violência, apego ao presente -, não mereceriam ser conservadas, quando de mudança completa da estrutura social?

\section{ESBOÇO DE UMA CRÍTICA}

Esses aspectos positivos não devem nos fazer esquecer as sérias críticas que numerosos antropólogos e sociólogos têm feito tanto ao método de Lewis quanto à sua concepção de objetividade científica (certos pontos de discussão sobre a noção de "cultura de pobreza" e sobre a teoria da sociedade que a sustenta serão propostos na terceira parte deste artigo). Se, em princípio, é correto, como afirmam alguns, utilizar o método do estudo de caso - com apoio principalmente da técnica das entrevistas aprofundadas - como instrumento de análise antropológica, uma estrita determinação dos critérios de escolha é, então, indispensável. Seguidamente, falta esta determinação nos trabalhos de Lewis. Quando do lançamento de "The Children of Sanchę", a revista americana Current Sociology enviou a 55 pesquisadores três das obras de Lewis. Suas respostas mostravam uma crítica muito generalizada: Lewis é muito sucinto na explicação dos fundamentos da escolha de certas famílias em lugar de outras. Seus critérios se desconhecem, da mesma forma que se ignora em função de que fatores ele efetuaria a escolha de uma região e, nesta região, de uma cidade, dos primeiros contatos e da família dos informantes ${ }^{19}$. Mesmo se uma definição clara do "terreno" de análise tivesse sido dada previamente, falta nos estudos de Lewis o emprego da comparação, este instrumento de trabalho indispensável em ciências sociais. Como, de fato, testar a veracidade de uma informação se não se a confronta com seus dados reais? Como apreender a representatividade dos casos escolhidos se não os situa em relação a outros casos, semelhantes ou diferentes? Como elaborar um conceito geral - "cultura de pobreza" - sem se contar com os meios dessa generalização?

Isso nos leva a levantar outro problema: Lewis afirma que ele transcreve diretamente, literalmente, as entrevistas, a fim de evitar interpretá-las demais em função de seus próprios "padrões" de norte-americano de classe média ${ }^{20}$. A intenção é, em princípio, louvável. Entretanto, é perigosa, na medida em que, privado de todo elemento de comparação, o pesquisador é obrigado a considerar 
que o que declaram seus informantes é a versão final e objetiva da verdade do problema. O risco é grande de cair no realismo sociológico daqueles que fariam coincidir, automaticamente, o que as pessoas dizem com o que querem dizer. De qualquer modo, Lewis manipula a informação recebida - e isso é necessário! porque ele dirige de perto a orientação das entrevistas e procede, ulteriormente, a uma verdadeira "montagem" dos textos em função de sua publicação ${ }^{21}$. Teme-se, contudo, que as exigências de um editor não sejam, neste caso, muito diferentes daquelas do pesquisador. Além da utilização do material ou da escolha dos instrumentos, uma objeção de fundo deve ser feita à concepção de Lewis: o emprego da família como imagem típica ou paradigma da sociedade. Esta opção, que explica o método de Lewis, põe-nos na pista de uma das principais dificuldades metodológicas de sua abordagem. Segundo a opinião da antropologia cultural tradicional, especialmente a de Radcliffe-Brown, que considera a família como uma sociedade em miniatura, Lewis parte da família para explicar a sociedade inteira, como se a sociedade fosse qualquer coisa visível, imediatamente analisável, e como se esta sociedade apenas se definisse pelos canais de comunicação consciente e voluntária - entre os indivíduos.

A antropologia estrutural contesta esta afirmação mostrando que a estrutura social denota um modelo abstrato construído pelo antropólogo para abordar uma realidade sempre movente, e que essa deve ser analisada em relação a um sistema complexo de funções e de inter-relações, cuja "comunicação social" representa apenas um aspecto ${ }^{22}$. Essas críticas levam a questionar a generalização do conceito de "cultura de pobreza" e, no limite, esse conceito em si. Porque, qual é o valor explicativo de um conceito obtido por meios tão criticáveis? E qual poderia ser o valor operacional de uma problemática baseada sobre a noção de "cultura de pobreza", da qual não se poderia explicitar exatamente nem as características nem o alcance? (A discussão sobre as causas da "cultura de pobreza" será abordada na terceira parte deste artigo).

\footnotetext{
21 LEWIS, O. La Vida... Op. cit., p. 781-782.

22 BATTELLI, P., na Revista Latino-americana de Sociología, 69-2, p. 426-427.
} 


\section{PAULO FREIRE: O SILÊNCIO DOS POBRES, NEGAÇÃO DE TODA CULTURA}

\section{O HOMEM E SUA OBRA}

Vivendo atualmente na Suíça, onde dirige um centro internacional de documentação sobre a educação, mas tendo passado toda a sua vida na América Latina, como pedagogo, Paulo Freire é um bom exemplo de homem que realiza em si mesmo o que ele prega para os outros. Ele iniciou este trabalho há mais de 20 anos, como professor de Filosofia da Educação no Nordeste brasileiro, elaborando, pouco a pouco, um sistema de educação de massas que pudesse ser um instrumento eficaz de desenvolvimento dos pobres e, ao mesmo tempo, ocasionasse uma tomada de consciência de seu destino, mediante sua participação ativa na sociedade. Para realizá-lo, ele se pôs o problema da educação de adultos e, num primeiro tempo, o da alfabetização, demonstrando, já em 1962, que era possível ensinar a ler e a escrever a um grupo de adultos analfabetos em menos de seis semanas. Encorajado por esse sucesso, o governo brasileiro de João Goulart encarregou-o de organizar uma intensa campanha de alfabetização na cidade do Recife. Dois milhões de pessoas deveriam beneficiar-se; somente 200 mil puderam fazê-lo porque um movimento político derrubou o governo e, com ele, essa ação de alfabetização de adultos. Obrigado a deixar o país, Freire passou quatro anos no Chile, trabalhando num programa de educação de adultos, integrado ao processo de reforma agrária em curso neste país.

Paulo Freire é, hoje, amplamente conhecido na América Latina. Seu método é aplicado em muitos países de nosso continente: com os indígenas que falam três línguas na Guatemala, nas cooperativas camponesas no Equador, juntamente com o processo de reforma agrária no Chile, sobre os altiplanos do México, nas favelas de Buenos Aires. Utilizado, no mais das vezes, com os analfabetos, seu método aplica-se também nos meios urbanos já alfabetizados. Se queremos apresentar algumas das ideias-mestras de Freire, é que toda sua concepção nos parece animada pela mesma preocupação de revelar as verdadeiras raízes da pobreza e de fornecer aos que a sofrem instrumentos eficazes para dela se libertarem.

\section{AS RAÍZES HISTÓRICAS DA IDEOLOGIA DO POBRE}

Freire define menos explicitamente que Lewis, menos sistematicamente também, o grupo social ao qual se dirige. Mas os marginalizados, ele os conhece bem. Viveu por muito tempo junto deles. Pode igualmente se beneficiar das 
contribuições de numerosos autores latino-americanos que estudam há mais de uma década o problema da marginalidade como característica da dependência ${ }^{23}$ Ao longo de sua ação pedagógica, ele empreendeu, igualmente, numerosas pesquisas junto aos marginalizados, pesquisas sobre a estrutura de sua linguagem e sua relação com diversos condicionamentos sociais ${ }^{24}$.

Sua reflexão sobre a pobreza na América Latina revela, portanto, os traços de uma verdadeira análise que se desenvolve em dois momentos sucessivos e complementares.

\section{ESTRUTURA SOCIAL E IDEOLOGIA}

Em um primeiro momento, Freire estuda o problema da estrutura social e da ideologia que dela decorre. Isto tem sido particularmente desenvolvido em sua obra "Educação como prática de liberdade"25. Pode-se afirmar que, até certo ponto, a um determinado estado da "infraestrutura", isto é, da organização das relações sociais em função das relações de produção, corresponde necessariamente um tipo de "superestrutura" ou ideologia. Uma determinada modalidade de organização social "provoca" representações mentais dessa situação que, seguidamente, se descobre a um nível subconsciente ou inconsciente.

Uma realidade social esmagadora não é, então, apreendida como tal imediatamente; ela é percebida mediante um número de representações que tendem a "acomodar" cada um à sua própria situação. As populações marginalizadas urbanas com as quais Freire especialmente trabalhou definem-se de certo modo por sua incapacidade de aceder aos serviços mais elementares. A marginalidade é fruto de uma segregação geográfica e institucional de todos os serviços sociais: educação, transporte, energia elétrica, trabalho, saúde pública, seguridade social, etc. Essa impossibilidade, mantida de geração em geração, provoca uma perda de toda a confiança em si mesmo e nos outros, uma mentalidade passiva e aberta a toda sorte de paternalismo. Em primeira aproximação, portanto, a análise de Freire aproxima-se muito daquela de Lewis.

23 Ver sobre este tema algumas publicações recentemente traduzidas em francês, onde se pode encontrar uma abundante bibliografia que faz referência ao problema da "dependência":

CARDOSO, F. H. Le sous-développement d'Amérique latine. Paris, Anthropos, 1969.

SANTOS, T. Dos. La crise de la théorie du développement er les Relations de dépendance en Amérique latine. In: Rev. L'Homme et la Société, abril, 1969.

RIBEIRO, D. L'enfantement des peuples. Paris: Cerf, 1971.

24 Ele desenvolveu esta ação no quadro do ICIRA (Centro interdisciplinar que funciona há cinco anos em Santiago do Chile e que publicou numerosos fascículos sobre o tema).

25 Trad. Francesa: Éducation: pratique de la liberté. Paris: Cerf, 1971.

Cf. Também: FREIRE, P. L'éducation pour la libération. In: Orientations, n. 40, pp. 27-37, oct. 1971; Cultural Action for Freedom, Harvard Educational Review, Monograph n. 1. 


\section{A LÓGICA INSTITUCIONAL}

Freire vai mais longe, num segundo momento, e isso é muito importante para nossa abordagem. Como resultado de seu contato com a massa imensa dos marginalizados, ele, progressivamente, descobriu que, na realidade, a situação de marginalidade responde primariamente não a uma vida atomizada no espaço ou no nível das funções, mas, sobretudo, a uma verdadeira "lógica institucional", espécie de disposição "segregacionista" natural, de inevitável tendência "marginalizante" das instituições sociais - escola, saúde pública, trabalho, etc. Freire ali encontra o enraizamento profundo nas modalidades segundo as quais foi realizada a colonização europeia na América Latina ${ }^{26}$.

Tendo como objetivo essencial a exploração comercial de nosso continente, os colonizadores espanhóis e portugueses somente poderiam impor-se brutalmente. O único critério de sua implantação era a apropriação, do que as "fazendas" brasileiras constituem o exemplo mais acabado. Esses grandes proprietários de terras representam, há três séculos, o lugar geográfico e o paradigma perfeito de um tipo de opressão social e mental. Nesses imensos territórios vazios da planície americana, vieram instalar-se aventureiros ibéricos que reduziram os indígenas à servidão, graças a uma força técnica e militar superior. Esses patrões autoritários, longe das cidades e das instituições coloniais, acabaram por transformar as "fazendas" em pequenos estados, verdadeiras monarquias absolutas e despóticas. Supostos "protegidos" do senhor, os indígenas escolheram a única forma possível de subsistir, de estar em segurança quando das frequentes incursões dos cangaceiros (bandos de pilhadores), e de estar em contato com um mundo exterior, longínquo, certamente, mas de onde vinham os produtos do progresso.

Nessas condições, os camponeses habituaram-se a viver na mais estrita dependência de seus patrões. O tipo de suas relações recíprocas era o paternalismo, a condescendência de um homem adulto em relação aos "minus", ou, em todo caso, menores. Nesse mundo estruturado verticalmente, o diálogo tornou-se logo impossível. Somente o patrão falava, o grupo de camponeses escutava; ele dava as ordens às quais os peões obedeciam; ele explicava o porquê da chuva, da terra, do trabalho, de Deus, da vida e da morte, e os camponeses aquiesciam. Essa foi

\footnotetext{
26 Apesar de Paulo Freire referir-se particularmente ao caso do Brasil, numerosos estudos feitos em outros países sugerem a possibilidade de se generalizar para toda a América Latina as afirmações que seguirão. Ver Éducation, pratique de la liberté (edição espanhola, cap. 2).
} 
a civilização de um só que falava ${ }^{27}$ e de uma multidão que se calava. Essa "lógica institucional" marcou profundamente a vida de nosso continente, criando o que Paulo Freire chama uma "cultura do silêncio".

Seria, portanto, enganoso compreender a marginalidade somente a partir da linguagem dos marginalizados. A marginalidade deve, antes tudo, ser entendida como o "mutismo" de todo um povo que foi reduzido ao silêncio pela força. Certo, os subproletários falam. Lewis fez bem de nos restituir sua linguagem. Mas de que se trata, ao certo? Mais que de uma linguagem própria, original, trata-se aqui de uma linguagem emprestada pelos servos de seus próprios mestres. Raciocinando como Hegel, quando ele explica a dialética do mestre e do escravo, Freire levanta a hipótese de que não somente os camponeses se calaram, mas que eles assimilaram - "introjetaram", diz Freire - essa autoridade exterior, adotando, pronta e inconscientemente, sua linguagem. Essa não é uma simples hipótese. Em suas próprias pesquisas, Freire pôde estabelecer até que ponto as instituições criadas pelos colonizadores eram instrumentos de dominação, e como certas entre elas - a educação, a igreja e, mais tarde, a técnica, e mesmo a teoria social - exerceram um papel objetivo de "legitimação" da dominação exercida, propondo aos dominados atitudes, raciocínios e objetivos que necessariamente os conduziria à aceitação indefinida dessa situação opressiva. Que essa "estratégia" de manutenção do status quo tenha sido mais ou menos consciente não diminui em nada sua eficácia real ${ }^{28}$.

\section{CULTURA DA POBREZA OU IDEOLOGIA DA DEPENDÊNCIA}

\section{O MECANISMO DA INTROJEÇÃO}

Desse modo, a pobreza e a cultura que dela resulta não deveriam ser analisadas somente em função de uma organização social, atual ou antiga, que teria produzido a segregação de uma grande massa da população rumo à periferia geográfica ou institucional da sociedade. Essa constatação é, para Freire, apenas o ponto de partida para mostrar que a marginalidade dos pobres só existe,

\footnotetext{
27 O mestre era o único a falar - "função" que poderia ser preenchida pelo patrão, pelo chefe militar ou administrativo ou pelo padre. Os camponeses compreenderam que esses eram os detentores de uma mesma força e, nisso, objetivamente cúmplices. Ver Éducation, pratique de la liberté (edição espanhola ou portuguesa, cap. 1).

28 Sobre os mecanismos da "introjeção", ver:

FREIRE, P. Pedagogy of the Oppressed. New York: Herder and Herder, 1967 (cap. 1 e 2).

Uma apresentação sumária poderá ser encontrada em:

SILVA, A. La pédagogie de Paulo Freire. Une conception politique de la Culture. Études, déc. 1970; L'éducation pour la liberté: un éclairage de la pédagogie de Paulo Freire. In: Perspectives, v. III, n. 1, 1973, pp. 43-49.
} 
como tal, quando os pobres, tendo perdido sua própria língua, em razão de um longo silêncio, adotam - para se comunicarem com os outros e explicarem-se a si mesmos - uma linguagem que é a do patrão e "daqueles que são como o patrão". Esse silêncio, efetivamente, tinha sido imposto aos camponeses pelo tipo de estrutura de dominação a que se submetiam - e cuja última expressão é a marginalidade urbana -, fruto da crença errônea de que a causa de seu infortúnio era a pobreza do campo e que, na cidade, sua vida poderia mudar. Entretanto, se a pobreza quase jamais se converteu em fermento de revolta ou em desejo de mudança, porém em destino inevitável ao qual se acaba por resignar-se, isto ocorre porque foi aceita uma ideologia que lhe explica o caráter "eterno" ou "natural" de uma sociedade profundamente desigual. Seja por meio de uma "religião" que prega a paz como resignação ou o amor como respeito a toda a ordem estabelecida: "pobres, sempre os tereis entre vós"; seja, mesmo, por meio de uma "teoria do desenvolvimento" que explica que o progresso é uma tarefa individual e que a função de cada um depende de sua qualificação, sendo esta proporcional à "inteligência" de cada homem" ${ }^{29}$.

Aceitando tais explicações, o camponês, o marginalizado e o pobre "introjetam" os valores do dominador. Essa "lógica institucional" e a "introjeção" resultante irão constituir no homem marginalizado o que Freire chama de uma "consciência dual", composta de dois elementos contraditórios: a percepção imediata de sua própria desgraça - basta abrir os olhos para lhe descobrir os traços: fome, lama, morte, horror, exploração -, e uma falsa explicação da realidade - em função de uma linguagem, de critérios e crenças que o levam a crer que é ele, em última instância, o único e principal responsável de sua miséria ${ }^{30}$. Se, por um lado, o homem dominado percebe sua exploração no presente, ele não está consciente disto na medida em que, não dispondo de meios próprios para racionalizá-lo, analisar e expressar, vive na tensão de quem não sabe o que lhe ocorre e o que pode fazer para livrar-se dessa situação. Vivendo, de fato, uma vida que the tem sido ditada pelo mestre, o servo acaba por conformar-se a este, cada vez mais fielmente. A penúria que não pode suprimir em si mesmo, ele a explica de diversas formas. De uma forma mágica, em alguns casos, colocando a realidade diretamente entre parênteses, preferindo explicações maniqueístas, naturistas ou falsamente religiosas: "é o destino", "Deus quer", "estou condenado a isto"... Ou de uma forma intransitiva, incapaz de situar "seu caso" no contexto social e numa perspectiva histórica ${ }^{31}$.

29 Sobre o efeito ideológico das técnicas e das teorias sociais ver ¿Extensión o Communicación?, Santiago, Chile, ICIRA, 1969, pp. 37-50.

30 FREIRE, P. Pedagogy of the Oppressed... Cap. 2.

31 FREIRE, P. Éducation, pratique de la liberté. (edição espanhola: pp. 49, 56-60).

976 - Rev. Bras. Polít. Adm. Educ. - v. 37, n. 2, p. 961 - 985, mai./ago. 2021 
O sistema de valores, de crenças e de normas, as modalidades de adaptação e de transformação da natureza que disto decorrem não podem, em tal perspectiva, ser consideradas como uma verdadeira cultura. Como pensar, de fato, que um homem que vive na dualidade, a ponto de equivocar-se, seria capaz de transformar a natureza, de comunicar-se verdadeiramente com seu meio, de construir solidariamente a história? A estrutura social o impede. O homem da pobreza é essencialmente um dominado, alguém que não pode representar-se, a não ser identificando-se ao "retrato", servil e imperfeito, do dominador. Antes que de uma "cultura de pobreza", seria melhor, na perspectiva de Freire, falar de uma ideologia da dependência, para melhor ressaltar até que ponto o mundo da marginalidade não goza de autonomia e explica-se, totalmente, no e pelo mundo central do poder ${ }^{32}$.

\section{UMA CONFRONTAÇÃO NECESSÁRIA}

Em torno de uma mesma interrogação sobre a condição do pobre latino-americano, tentamos apresentar, esquematicamente, duas posições muito diferentes: de Oscar Lewis e de Paulo Freire. Arriscando simplificar seus pontos de vista, quisemos simplesmente apresentar sua maneira de problematizar a pobreza em nosso continente. É necessário, agora, alargar essa análise a fim de identificar certos traços de suas respectivas concepções da sociedade. Faremos isto, sucintamente, comparando suas visões da organização social. Pensamos que essa confrontação não é mais que um esboço do debate que mereceria ser travado em torno de dois tipos divergentes de concepção do desenvolvimento de nosso continente.

\section{A SOCIEDADE, SEGUNDO OSCAR LEWIS}

Certamente, Lewis marca um avanço em relação às concepções da antropologia dominante nos Estados Unidos, seu país. Em suas análises do mundo da pobreza, integra, em especial, os aspectos conflituosos das relações do pobre com seu entorno. Reestudando o vilarejo mexicano de Tepostlan, acerca do qual o antropólogo americano Redfield tinha formulado pontos de vista que puderam, à época, parecer definitivos, Lewis mostrava, já em 1951, a necessidade de deixar a análise do mundo dos "slums", de uma perspectiva simplesmente funcionalista, que daria da realidade social "uma imagem demais integrada, demais estável, ainda totalmente imbuída de um romantismo rousseauniano 
sobre as sociedades primitivas" ${ }^{33}$. O autor tem o mérito de sublinhar que esta "cultura de pobreza", da qual fala, nasceu no mundo do capitalismo, do qual é uma consequência. Ele ultrapassa, assim, uma concepção puramente pejorativa da cultura dos marginalizados, outrora considerada como um resto atrasado de um mundo tradicional e decadente, e parece abrir uma perspectiva em que a cultura e o meio social se explicariam dialeticamente, mutuamente, sendo ambas variáveis interdependentes para estudar um mesmo problema: a estrutura social.

Infelizmente, Lewis permanece aí e quase nenhuma consequência metodológica decorre dessa precedente declaração de princípios. Ao invés de mostrar como o homem situa-se em um contexto social que o explica, ele isola cada homem no seio de sua família. Cada vez mais, entretanto, os antropólogos contestam que a partir de simples estudos de caso possam ser abordados os verdadeiros problemas sociais que se põem numa comunidade, ou que a família possa ser considerada seriamente como uma sociedade em miniatura. Igualmente, em lugar de empreender a pesquisa das raízes históricas da "cultura de pobreza" - que sua fé anticapitalista levaria a prever -, ele situa o problema num presente permanente, sem gênese e sem perspectivas reais de transformação. Assim, privase de compreender as verdadeiras causas da "cultura de pobreza" e as funções que ela, efetivamente, preenche em cada etapa da evolução social do México, país onde ele efetuou a maioria de suas pesquisas. Lewis limita-se a uma simples descrição e, neste sentido, permanece no exterior dos grupos estudados, apesar de seu grande esforço de integração.

\section{PAULO FREIRE: UMA SOCIEDADE DE DOMINAÇÃO}

Vindo de outra tradição intelectual, Paulo Freire supera essas diferentes armadilhas, a nosso ver de forma bem-sucedida no seu conjunto. Partindo do fato de que o homem se explica por seu meio social, a análise de Freire esforça-se em utilizar instrumentos que permitam identificar as determinações que fazem com que o homem seja, em grande medida, um produto fiel do mundo social no qual se situa, quer ele queira ou não. Em segundo lugar, as relações sociais, que são, de fato, relações de grupo a grupo, realizam-se sob forma de tensões e de conflitos. A sociedade que Freire vê é definida historicamente pela luta de classes. Uma tal sociedade rege-se por uma "lógica de dominação", pela qual os mais poderosos remodelam inteiramente a estrutura social à sua imagem e segundo seus interesses. Nenhuma marginalidade, portanto, é possível se entendida como a coexistência de duas sociedades, uma tradicional e a outra moderna, justapostas uma à outra

33 Esta opinião é de Guy Rocher em sua obra Introduction à la Sociologie Générale. Tomo 2, "L'organisation sociale". Paris, edição HMH, 1970, p. 126. Ver também o Tomo 3, p. 104.

978 - Rev. Bras. Polít. Adm. Educ. - v. 37, n. 2, p. 961 - 985, mai./ago. 2021 
e gozando de certa autonomia mútua, apesar de suas diferenças de nível de progresso e da quantidade de riquezas. Uma análise em termos de "dualismo" não é igualmente correta porque, na realidade, a sociedade "moderna" mantém sob seu controle o mundo tradicional: é porque este permanece um mundo tradicional que aquela chega a ser uma sociedade moderna. O que é verdadeiro do ponto de vista social, o é igualmente do ponto de vista cultural. Pensamos que Freire consideraria ilegítimo o fato de se analisar como relativamente autônoma uma cultura que, definitivamente, não é mais que o reflexo da cultura dominante. Diferentemente de Lewis, Freire pensa que é na origem histórica de nossas sociedades que se deve buscar a explicação de nossa cultura, de nossas culturas, e que é numa leitura renovada da história do continente que poderemos encontrar o caminho da superação de nossas deformações culturais.

\section{“CULTURA DE POBREZA” E "CULTURA DO SILÊNCIO"}

Ainda que mais descritiva, talvez, que a de Freire, a perspectiva de Lewis não nos parece a mais correta para identificar de modo preciso o problema das relações entre a marginalidade social e a cultura na América Latina. Inclusive, a expressão "cultura de pobreza" parece-nos necessitar uma utilização prudente e sujeita a uma cuidadosa crítica prévia. Uma forma de efetuar esta crítica poderia ser, em nossa opinião, comparar os conceitos de "cultura de pobreza" e de "cultura do silêncio". Sugeriremos, agora, alguns elementos para esta comparação.

\section{POSITIVIDADE OU PRIVAÇÃO?}

Parece-nos, primeiro, que falar de "cultura de pobreza" supõe que se acentue o aspecto produtivo da vida social dos marginalizados. Isso significa afirmar que, apesar das miseráveis condições de vida, a dominação não é suficientemente impositiva para impedir que os marginalizados organizem um "código" que lhes seja próprio. Eles teriam suficiente autonomia para elaborar um sistema permanente e fecundo que mereceria ser considerado como uma cultura. Lewis insiste sobre o que existe de positivo na "cultura de pobreza". É verdade, parece dizer, que os pobres são explorados, mas eles possuem um folclore muito lindo, são muito acolhedores, sentem-se muito solidários em relação aos outros. Considerada a partir da reflexão de Freire, a "cultura" dos marginalizados distingue-se essencialmente por suas carências. É algo que tem sido roubado, expropriado, substituído por uma cultura de ricos. Se é verdade que os pobres cantam bem e são muitas vezes joviais e simpáticos - o que não lhes é de forma alguma exclusivo! -, não se pode ficar nisso. 
A cultura é transformação do mundo, comunicação com os outros homens, decisão livre e solidária de fazer a história: a "cultura de pobreza" tem tais características e permite, verdadeiramente, avançar no sentido de uma humanização? Pondo-se essa questão, Freire é obrigado a insistir sobre o fato que um marginalizado é culturalmente alguém privado dos valores essenciais e de si mesmo, isto é, "castrado". Freire renuncia a todo tipo de romantismo da pobreza, que poderia conduzir à idealização da vida dos pobres.

\section{A SITUAÇÃO DE DOMINAÇÃO}

Falar de "cultura de pobreza" parece igualmente supor que de uma infraestrutura de dominação pode surgir um sistema cultural autêntico, conjunto coerente de valores que dariam sentido à vida e tornariam possíveis ações livres. Freire prefere falar de "cultura do silêncio", querendo afirmar que a dominação infraestrutural é prioritária e determinante. Somente quando a estrutura injusta for abolida é que poderão ser criadas as condições de um desenvolvimento cultural durável. O projeto cultural de Freire realizar-se-á na medida em que essas condições chegarão um dia a ser substancialmente mudadas (seu método é exatamente um instrumento para tanto). Enquanto Lewis parece pensar que a "cultura de pobreza", em última instância positiva, poderá explodir e desenvolverse, tal como se dá atualmente, quando as condições sociais serão modificadas.

A causa desta nítida diferença de ótica reside, provavelmente, no fato de que o ponto de partida dos dois autores não coincide. Seríamos tentados a afirmar que Lewis trabalha numa perspectiva sobretudo psicológica, tendendo, assim, a reduzir o problema social da marginalização a uma sucessão de casos particulares. Ora, tratar dos problemas sociais como se tratasse de casos específicos, significaria reduzir a mudança social a uma simples multiplicação de conversações pessoais. A estrutura global não é, assim, posta em questão, tratarse-ia somente de "reintegrar" os desviantes e de sustentar os fracos. Optando por um ponto de vista simplesmente psicológico, Lewis limita abruptamente o alcance da tomada de consciência que queria provocar, transformando seus escritos em pura denúncia escandalizada das situações, cuja visão "dói no coração". Mais que isso, a ação que ele aspira desencadear não vai além da melhor tradição da "ajuda" que os países ricos "concedem" aos países pobres. Assim, concluímos a partir de afirmações do próprio Lewis em "La Vida": 
Um dos principais objetivos desta obra é de preencher esta lacuna na comunicação entre os muitos pobres e os servidores - professores, assistentes sociais, médicos, padres e outros - a quem incumbe especialmente a responsabilidade de realizar os programas de luta contra a pobreza. Espero que uma melhor compreensão da natureza da cultura de pobreza levará, finalmente, a considerar com mais compaixão os pobres e seus problemas e disporá de uma base mais racional para uma ação social construtiva ${ }^{34}$.

Freire serve-se, ao contrário, de uma metodologia tipicamente sociológica, vinculando o homem e seu meio social ao conjunto da sociedade e explorando os laços que ligam uns aos outros. Tendo concluído que a "cultura", nascida da marginalidade, é sobretudo uma "superestrutura", no sentido marxista do termo, ele não se limita a denunciar a situação. Empenha-se em promover uma "práxis libertadora" que permita pôr fim ao conjunto de causas dessa dependência.

\section{A DEMOCRATIZAÇÃO DA CULTURA E A IGUALDADE DE OPORTUNIDADES}

Como havíamos sugerido no início deste artigo, a diferença mais profunda entre os dois autores analisados reside no que pretendem dizer quando falam de "dar a palavra" aos marginalizados, e no que querem fazer de concreto para a transformação da alienação cultural de nosso continente.

\section{DAR A PALAVRA AOS MARGINALIZADOS}

A tarefa evidente que se impõe é a de "democratizar a cultura". Entretanto, este objetivo foi tradicionalmente entendido como um esforço para fazer com que muitos participem do que poucos aproveitam atualmente: o patrimônio cultural consagrado por séculos e sancionado por um sistema permanente de transmissão do saber. $\mathrm{O}$ instrumento por excelência para realizar essa perspectiva foi, desde então, uma rede escolar, a mais extensa e completa possível, assegurando às massas um verdadeiro "acesso à cultura". Para muitos, a democratização da cultura foi - e continua a ser - uma simples consequência da abertura a todos dos locais tradicionais de ensino, efeito previsível do que chamou "igualdade de oportunidades" ${ }^{\prime 35}$.

\footnotetext{
34 LEWIS, O. La Vida... (edição francesa: p. 71).

35 Não éa isso que se dirigem certos esforços de planificação da educação que não levam suficientemente em conta as restrições sociais e ideológicas existentes? Ver sobre este tema: Aspects économiques et sociaux de la planification de l'éducation, Paris, UNESCO, 1963 (cap. 1).
} 
É, portanto, legítimo falar de "igualdade de oportunidades" nos países do terceiro mundo, ou antes, no continente latino-americano? O conceito mesmo de igualdade de oportunidades evoca numerosas observações críticas.

Se a cultura dos marginalizados é, de alguma forma, a expressão de um estado de dominação, parece dificilmente concebível que seja "entre" os dominantes - em seu sistema de transmissão cultural - que uma emancipação poderia ser efetuada. Levar a sério o problema da cultura alienada dos marginalizados significa denunciar a igualdade de oportunidades como uma estratégia que vai ao encontro da democratização cultural desejada. É nisso que a concepção de pedagogos como Paulo Freire poderia ajudar a refletir. Em seus escritos e em sua ação, "a palavra" não é, para ele, o instrumento de explicação que se toma emprestado de outros mestres esclarecidos, antes é um poder de comunicação e de ação que é preciso redescobrir e fazer nascer de novo em si mesmo. Combater a "cultura do silêncio" supõe, então, dar a cada um a possibilidade de expressar-se e de realizar sua própria palavra, de vê-la liberada e libertadora da sociedade na qual se vive.

Para muitos, a realização desta perspectiva é, certamente, resultado de uma mudança radical de estruturas na América Latina. Mas é possível, desde agora, optar entre dois tipos contraditórios de educação: uma educação para a domesticação, na qual o homem é considerado como objeto passivo ("pote de conhecimentos"), ou uma educação para a libertação que, desmontando os mecanismos que engendram a "cultura do silêncio", vê o ato pedagógico como parte de um processo global onde os homens tornam-se verdadeiramente "sujeitos" de sua própria história e construtores de cultura ${ }^{36}$.

\section{UMA CRÍTICA RADICAL DA ESCOLA}

Do acima exposto à contestação do atual sistema de educação é apenas um passo. É necessário fazê-lo para criticar globalmente este sistema, não apenas no nível de um arranjo institucional que favorece a deserção escolar; ou no nível dos "conteúdos de classe" que explicam a realidade de modo a justificar as classes dominantes. Uma questão mais radical, posta por outros pedagogos, visa a existência mesma do sistema de ensino como portador de um tipo de técnicas de socialização implícitas ${ }^{37}$. Pergunta-se cada vez mais vigorosamente se a "escola" não é o lugar onde a criança, o jovem ou o jovem adulto, assimila

\footnotetext{
36 Expor a metodologia de Paulo Freire ultrapassa nosso objetivo aqui. Ver sobre este tema a exposição muito clara e concisa da revista IDOC: "Paulo Freire: une révolution mondial de l'éducation". Paris, Ed. Du Seuil, n. 29 , p. 29-63.

37 No sentido do artigo de Charles Roig: "Les Études de Socialistion politique des enfants: essai de bilan", In: Orientations, n. 33, jan. 1970, p. 37-54.
} 
uma visão passiva da realidade, uma atitude simplemente receptiva e mecânica e uma bagagem de comportamentos que "preparam” este público maleável para a "obediência" conformista que deverão mostrar diante do poder estabelecido e de suas hieraquias quando cidadãos. Se essa afirmação fosse verdadeira - e muitos estudos recentes o confirmam ${ }^{38}$-, isso quereria dizer que quanto mais existir escolarização, mais a "cultura" escolar será "vulgarizada", no sentido próprio do termo, com as consequências previsíveis - e, em parte, já confirmadas - de "recuperação" dos neo-escolarizados pelo sistema de valores dominante. A "democratização", concebida estritamente como uma escolarização, tende facilmente, na conjuntura latino-americana atual, a fazer o jogo das forças de domesticação, inculcando em um número cada vez maior de crianças modelos tradicionais que "fixam" nas consciências o status quo atual, tais como certos modelos tecnocráticos, em função dos quais a formação é concebida a partir da estrita necessidade de mão de obra.

O que fazemos aqui é levantar, muito rapidamente, o grave problema da escolarização, para sugerir até que ponto o sucesso da atual política de "igualdade de oportunidades" corre o risco de causar, no longo prazo, a alienação, assim como a destruição progressiva das culturas nacionais.

Apesar das aparências enganosas, uma política de democratização pela escolarização ${ }^{39}$ tornou-se, muitas vezes, na América Latina, o oposto de um verdadeiro empreendimento de democratização da cultura. Não se deve, entretanto, acreditar que esse necessário questionamento do conceito de igualdade de oportunidades é uma exigência apenas dos países do terceiro mundo, às voltas com a pobreza e tendo regimes de poder absoluto e sem partilha. É preciso reconhecer que os "modelos" veiculdos pelo sistema de educação de nosso continente foram deveras importados do "Velho Continente", e que este sistema parece exercer, igualmente na Europa, um poderoso papel de "reprodução social", que assegura a transmissão de um tipo de cultura burguesa ${ }^{40}$.

38 Ivan Illich, em muitas ocasiões, levantou esse problema, propondo diretamente um ponto de partida novo, não escolar, da educação e recolocando a problemática da "sociedade educativa". Ver, por exemplo: "L'école, cette vache sacrée". Revue Les Temps Modernes, n. 280, p. 673-683, nov. 1969; "La futilité de l'école en Amérique Latine". Revue Orientations, n. 33, p. 19-35, jan. 1970; "Pour en finir avec la religion de l'école". Revue Esprit, P. 835-850, dez. 1970.

39 Consideramos provisoriamente que o termo "democratização" corresponde à "igualdade de oportunidades" e que o acesso à escola já é uma vitória aos olhos dos que lutam pela extensão universal da escola.

40 Pierre Bordieu tem estudado profundamente este problema. Ver, por exemplo, "L'excellence scolaire et les valeurs du système d'enseignement français", Paris, CSE, 1969; "Reproduction culturelle et reproduction sociale", Paris, CSE, 1970. 
A mesma questão sobre a legitimidade da noção de igualdade de oportunidades poderia ser posta em relação à França, país em que diferentes partidos políticos - sobretudo de esquerda - puseram a "democratização" do ensino no topo das reivindicações políticas em matéria de educação. Chegar-se-ia, assim, ao termo de concessões arrancadas por um povo "sedento de instrução"; as forças conservadoras teriam apenas concedido o instrumento que lhes traz de volta todas as camadas da sociedade, novamente uniformizadas em função de uma "cosmovisão" profundamente desigualitária. Isso mostra a ambiguidade da noção de igualdade de oportunidades, por longo tempo interpretada como uma espécie de "elevador social", acerca de que se poderia iniciar uma crítica em torno de problemas como, por exemplo: se a igualdade de oportunidades é entendida como a obtenção por todos das mesmas possibilitades de acesso ao ensino, não haveria o perigo de se impor uma via "cultural" única a grupos sociais com visões divergentes ou opostas? (problema já citado, da domesticação pela escolarização). Se essa igualdade é concebida igualmente como uma eliminação da deserção escolar e como uma diversificação de conteúdos e de métodos pedagógicos, fica claro que, diante do ensino, nenhuma "igualdade de oportunidades" é possível enquanto não sejam efetudas pelos governos profundas reformas estruturais. Isso conduz à questão da eficácia econômica e social de um ensino verdadeiramente igualitário: ainda que o problema do emprego seja solucionado, o da cultura não o é - em função de que sistema (ou de que projeto) social pensar a educação?

Dado que tais questões são válidas também na Europa, surge a necessidde de pensar o problema da democratização do ensino em perspectivas diferentes. Talvez seja preciso ultrapassar a estreiteza de certas perspectivas atuais simplesmente quantitativas - critérios de custo-benefício, de necessidade de mão de obra e de produção - e visar uma educação concebida como "aprendizagem da liberdade". Uma educação como simples adaptação ao meio cederia, então, seu lugar a outra que encoraja a transformação radical da sociedade. É possível que, renunciando a seu papel de mantenedora da ordem cultural atual, essa nova educação contribuiria para a criação de novos "padrões" culturais. 


\title{
REFERÊNCIA DA PUBLICAÇÃO ORIGINAL
}

SILVA, A.; SGUISSARDI, V. Culture de pauvreté, domination et pédagogie de la libération. Orientations, t. 13, n. 47, p. 49-72, juillet 1973.

\begin{abstract}
Alberto Silva
Historiador, Filósofo e Sociólogo, com Mestrado em Sociologia (sob orientação do professor Pierre Bourdieu) e Doutorado em Letras e Ciências Humanas na Universidade de Paris (Sorbonne) e Doutorado em Ciências Políticas (Ministério da Educação da Espanha), tendo realizado pós-doutorado com os professores Roland Barthes e Claude Lévi-Strauss. Foi professor nas seguintes universidades: Universidade Católica de Santiago, Universidade de Paris (Vincennes), Universidade de Lisboa, Universidade Autônoma de Barcelona (Professor Titular de Sociologia), Universidade Sophia de Tóquio, Universidade de Quioto (Catedrático em Estudos Estrangeiros), tendo sido ainda especialista da Unesco em missões na Tunísia, Níger e Portugal. E-mail: betosilvacastro@gmail.com
\end{abstract}

\section{Valdemar Sguissardi}

Licenciado em Filosofia pela Universidade Regional do Noroeste do Estado do Rio Grande do Sul (1966), mestrado em Science de lÉducation - Université de Paris X, Nanterre (1972) e doutorado em Sciences de lÉducation - Université de Paris X, Nanterre (1976). Professor Titular aposentado da Universidade Federal de São Carlos (1992) e professor aposentado da Universidade Metodista de Piracicaba (2010). Tem experiência na área de Educação, com ênfase em Fundamentos da Educação, atuando principalmente nos seguintes temas: educação superior, política de educação superior, reforma da educação superior, público e privado na educação superior. E-mail: vsguissardi@gmail.com 